\title{
Effects of a comprehensive reservation service for non-emergency registration on appointment registration rate, patient waiting time, patient satisfaction and outpatient volume in a tertiary hospital in China
}

Wanhua Xie ${ }^{1 *}$, Xiufeng Yang ${ }^{2}$, Xiaojun Cao ${ }^{2}$ and Peiying Liư ${ }^{3}$

\begin{abstract}
Background: In China, a long waiting time for registration is a common occurrence in many tertiary hospitals. This study aimed to analyze the effects of a comprehensive reservation service for non-emergency registration on appointment registration rate, patient waiting time, patient satisfaction and outpatient volume at the Guangzhou Women and Children's Medical Center.

Methods: This was a cross-sectional study. This study investigated the effects of a comprehensive reservation service for non-emergency registration in Guangzhou Women and Children's Medical Center in China starting in October 2015. In total, 2194 patients completed a satisfaction survey administered by the Guangdong Situation Research Center. The content of the questionnaire consisted of six aspects: general impression, service attitude, service quality, hospital environment, price perception and medical ethics. A Likert 5-point rating scale was used in the questionnaire; answers were classified as "very satisfied", "relatively satisfied", "neutral", "unsatisfied" and "very unsatisfied". The method of application was paper-based. T-tests were used to compare the sample means, and chisquare tests were used to compare the rates. A multiple-test procedure was performed to evaluate the differences in the reservation rates during a 12-month period.

Results: After the implementation of the comprehensive reservation service for non-emergency registration in our hospital, which has an annual outpatient volume of approximately 4 million, the monthly appointment registration rate increased from $(34.95 \pm 2.91) \%$ to $(89.13 \pm 3.12) \%, P<0.01$. The patient waiting time was significantly reduced $(P<0.01)$, and the proportion of patients who believed that the waiting time required improvement was decreased significantly $(P<0.01)$. Moreover, the third-party evaluation result of outpatient satisfaction significantly improved $(P<0.01)$. The total hospital outpatient volume decreased $(P<0.01)$. The outpatient volume of the Department of General Pediatrics decreased.

\footnotetext{
*Correspondence: xiewanhua1@126.com

'Department of outpatient, Guangzhou Women and Children's Medical

Center, Guangzhou Medical University, Guangzhou, China

Full list of author information is available at the end of the article
}

(c) The Author(s). 2019 Open Access This article is distributed under the terms of the Creative Commons Attribution 4.0 International License (http://creativecommons.org/licenses/by/4.0/), which permits unrestricted use, distribution, and reproduction in any medium, provided you give appropriate credit to the original author(s) and the source, provide a link to the Creative Commons license, and indicate if changes were made. The Creative Commons Public Domain Dedication waiver (http://creativecommons.org/publicdomain/zero/1.0/) applies to the data made available in this article, unless otherwise stated. 
(Continued from previous page)

Conclusion: The implementation of the comprehensive reservation service for non-emergency registration in the hospital shortened patient waiting time and improved patient satisfaction, and the outpatient volume was effectively controlled. These results indicated that this program obtained the desired results in a Grade $3 \mathrm{~A}$ hospital in China.

Keywords: Comprehensive reservation service for non-emergency registration, Appointment registration rate, Waiting time, Patient satisfaction, Outpatient volume

\section{Background}

With the expectation of an increasing global population and an increase in overall life expectancy over the next 30 years, governments all over the world are striving to expand the scope of health services $[1,2]$. In addition, waiting time in outpatient clinics are regarded as substantial obstacles and needs to be reduced worldwide [3, 4]. Clinical practice has suggested that the appointment registration process is the responsibility of hospital management. Effective appointment registration services through telephone calls and messages has an impact on appointment adherence and clinical outcomes for patients with diabetes [5]. The current outpatient service system is faced with challenges regarding the effective arrangement of appointments and providing medical services to patients [6]. Ortiz Barrios [7] suggested that high-risk pregnant women may experience serious health complications due to prolonged appointment waiting time. In China, due to the development of the family doctor system and community hospital services, the family doctor appointment system remains under development. In addition to receiving referred patients, tertiary hospitals in China receive a large number of patients with mild diseases for the first time.

Hospitals in China do not demand that patients have a prescheduled appointment, and patients can either make an appointment in advance or come directly to the hospital for registration without making a prior appointment. Many patients prefer to see a well-known expert in a large hospital. A long waiting time for registration is a common occurrence of many tertiary hospitals in China; thus, effective management and diversion have become one of the main goals of health care reform in China. The Action Plan for the Further Improvement of Medical Services, issued by the National Health and Family Planning Commission, recommends improving the appointment registration rate of tertiary hospitals in China [8].

According to the satisfaction survey conducted by the Guangdong Situation Research Center (a third party) in the first quarter of 2015, the outpatient satisfaction score of our hospital was 81.07 points. Moreover, $67.33 \%$ of outpatient respondents suggested that the first step was to improve the waiting time, which remained a key point for improving the satisfaction with outpatient services in our hospital.
To shorten the waiting time of patients, gradually promote graded diagnoses and treatments, and encourage patients to seek medical treatment in a reasonable and orderly manner, the Guangzhou Women and Children's Medical Center implemented a comprehensive reservation service for non-emergency registration in China starting in October 2015; our hospital was the first to implement such a system in China.

The purpose of this study was to investigate the effects of a comprehensive reservation service for non-emergency registration and the optimization of medical service processes on appointment registration rate, patient waiting time, patient satisfaction regarding waiting time, satisfaction degree and outpatient volume.

\section{Methods}

Guangzhou Women and Children's Medical Center has implemented the comprehensive reservation service of non-emergency registration since October 2015. With the exception of emergency and isolated patients in the clinic, the remaining patients are encouraged to make an appointment using any of the following methods: a mobile phone (WeChat public platform, Alipay of Guangzhou Women and Children's Medical Center), the Yichengtong application (mobile application), the hospital website, interclinic appointment registration or appointment registration for subsequent visits after discharge, phone calls and an on-site self-service terminal.

Patients are mainly encouraged to use the mobile payment systems for online registration, as there is no need to queue for payment and obtaining a paper registration certificate in our hospital. The large number of patients who make appointments but do not pay in advance results in a large number of patients who visit the hospital to pay for a paper registration certificate after making the appointments. Among three districts with more than 12,000 outpatients per day, there was a longer queue. The comparison of outpatient medical service processes before and after the implementation of the comprehensive reservation service are shown in Fig. 1.

Combining reservation rules and information technology avoids wasting registration number resources and restricts speculative behavior. Our hospital has unified the appointment registration methods and has re-amended 


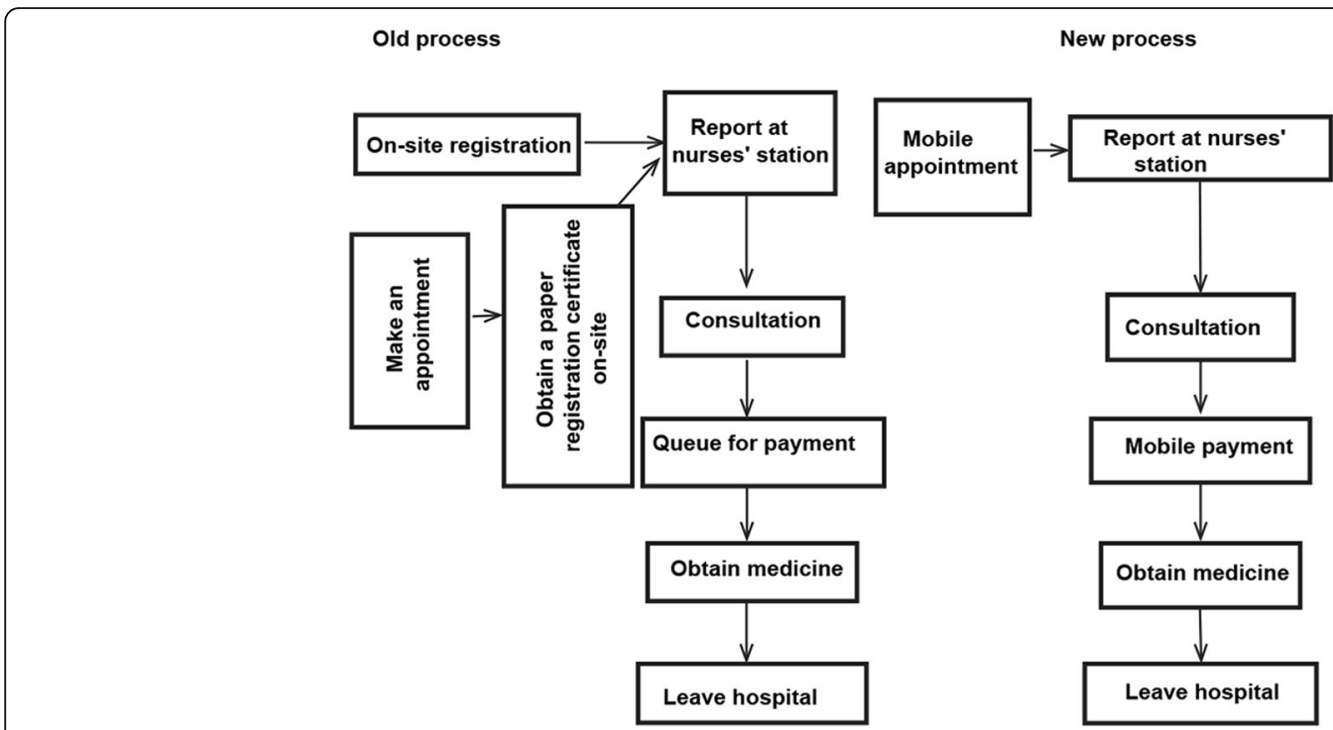

Fig. 1 Comparison of outpatient medical service processes before and after the implementation of the comprehensive reservation service of non-emergency registration

the appointment registration rules to strengthen the management of nonattendance at the clinic.

The Guangzhou Women and Children's Medical Center consists of Zhujiang New Town Hospital District, Child Hospital District and Maternal and Infant Hospital District. It is the largest specialist hospital for women and children in South China, and patients from all over the country are seen.

The appointment registration rate and outpatient volume data were obtained from the Business Intelligence System of our hospital. Data on patient satisfaction and the proportion of patients who believed that the waiting time needed improvement were extracted from quarterly survey results of the outpatient satisfaction survey conducted by the Guangdong Situation Research Center. Data collection took place from October 2014 to September 2016. The satisfaction survey was conducted onsite in the women and children's medical center. The method of application was paper-based. The survey was conducted by 60 trained investigators. During the first quarter of 2015, 2194 valid questionnaires were collected from the outpatient clinics; 982 questionnaires were collected from the outpatient clinic of Zhujiang New Town hospital District, 884 questionnaires were collected from the outpatient clinic of the Children's Hospital District, and 328 questionnaires were collected from the outpatient clinic of the Maternal and Infant Hospital District.

General satisfaction was the first-level indicator; there were six second-level indicators: general impression, service attitude, service quality, hospital environment, price perception and medical ethics. There were 31 third-level indicators. The responses to the third-level index were categorized by a 5 -point Likert scale. The answers were coded from 1 to 5: 1-very satisfied, 2-satisfied, 3-neutral, 4-unsatisfied, and 5-very unsatisfied [9, 10]. All of the questionnaire data were statistically analyzed by SPSS software. The current internationally recognized method for calculating the satisfaction degree on the basis of public opinion was adopted for calculating each of the thirdlevel indexes $[9,10]: 100$ points: "very satisfied", 80 points: "relatively satisfied", 60 points: "neutral", 40 points: "unsatisfied", 20 points: "very unsatisfied"; "unclear" was assigned

Table 1 Comparison of the monthly appointment reservation rates before and after the implementation of the comprehensive reservation service for non-emergency registration

\begin{tabular}{llll}
\hline & $\begin{array}{l}\text { Before } \\
\text { implementation(\%) }\end{array}$ & $\begin{array}{l}\text { After } \\
\text { implementation (\%) }\end{array}$ & $P$ \\
\hline January & 33.06 & 89.61 & 0.000 \\
February & 34.72 & 88.65 & 0.000 \\
March & 33.14 & 90.50 & 0.000 \\
April & 33.22 & 90.20 & 0.000 \\
May & 33.13 & 88.13 & 0.000 \\
June & 33.80 & 88.85 & 0.000 \\
July & 39.28 & 90.97 & 0.000 \\
August & 40.33 & 92.56 & 0.000 \\
September & 39.46 & 91.43 & 0.000 \\
October & 33.22 & 80.10 & 0.000 \\
November & 32.99 & 88.72 & 0.000 \\
December & 33.05 & 89.82 & 0.000 \\
Mean value & $34.95 \pm 2.91$ & $89.13 \pm 3.12$ & 0.000 \\
\hline *the P value was adusted to family-wise & correcta of 0.05 using bootstrap
\end{tabular}

*the $P$ value was adjusted to a family-wise corrected a of 0.05 using bootstrap permutation testing 
Table 2 Comparison of the waiting time for registration and waiting time for consultation before and after the implementation of the comprehensive reservation service for non-emergency registration

\begin{tabular}{|c|c|c|c|c|c|}
\hline Mode & Before implementation(minute) & After implementation(minute) & Time saved (minute) & $\mathrm{t}$ & $p$ \\
\hline Waiting time for registration & $25.05 \pm 8.17$ & $1.00 \pm 0.21$ & $24.05 \pm 7.31$ & 131.999 & 0.000 \\
\hline Waiting time for consultation & $60.30 \pm 9.26$ & $12.00 \pm 3.00$ & $48.30 \pm 9.73$ & 223.402 & 0.000 \\
\hline
\end{tabular}

$P<0.05$ : statistically significant

for missing values, which were excluded from the data analysis.The minimum and maximum possible values of the third-level indexes were 20 and 100, respectively (Additional file 1).

General satisfaction was calculated by summing the scores of all the second-level indicators after multiplying them by their assigned weights: general impression (5\%), service attitude (15\%), service quality $(20 \%)$, hospital environment $(10 \%)$, price perception $(20 \%)$, and medical ethics $(30 \%)[9,10]$.

\section{Statistical analyses}

IBM SPSS Statistics 23.0 software was used for the statistical analyses. The $\mathrm{W}$ test was used to evaluate whether the data were normally distributed. Independent samples $t$ test were used to compare the sample means of registration waiting time, consultation waiting time and outpatient satisfaction. Paired t-tests were used to compare the sample means of monthly outpatient volume, and a chi-square test was used to compare the rates. The multiple test procedure was performed to evaluate the differences in the reservation rates during a 12-month period. To correct for multiple comparisons, the $p$ value of each variable was adjusted to a family-wise corrected $\alpha$ of 0.05 using bootstrap permutation testing in SAS 9.4 for Windows software (SAS Institute, Inc., Cary, NC, USA 2015). $P<0.05$ was considered statistically significant.

\section{Results}

Regarding the questionnaires, female respondents accounted for 53.19\%, male respondents accounted for $46.81 \%$, Guangzhou residents accounted for $68.91 \%$, respondents living in other cities of Guangdong Province accounted for $26.47 \%$, respondents living in other provinces accounted for $4.39 \%$, and others accounted for $0.23 \%$.
The appointment registration rate was significantly increased after the implementation of the comprehensive reservation service for non-emergency registration.As shown in Table 1, our hospital had an annual outpatient volume of approximately 4 million, and the monthly appointment registration rate was significantly increased from $(34.95 \pm 2.91) \%$ to $(89.13 \pm 3.12) \%(P<0.01)$.

The hospital waiting time for patients and their family members were reduced. As shown in Table 2, the patient waiting time was significantly reduced after the implementation of the comprehensive reservation service $(P=0.000, P<0.01)$.

As shown in Table 3, after the implementation of the comprehensive reservation service, the proportion of patients who believed that the waiting time needed improvement was significantly decreased $(P<0.01)$.

As shown in Table 4, compared with 1 year before the implementation of the comprehensive reservation service, the quarterly satisfaction of outpatients was significantly increased 1 year after the implementation of the service $(P<0.01)$.

The total hospital outpatient volume decreased, and the Department of General Pediatrics outpatient volume decreased.Compared with 1 year before the implementation of the comprehensive registration service, the monthly total outpatient volume during the first year after implementation was significantly decreased $(\mathrm{P}<0.01)$ (Table 5). The comparison of monthly outpatient volumes 1 year before and after implementation is shown in Fig. 2. At 1 year after the implementation of the comprehensive registration service, the outpatient volume of the Department of General Pediatrics was 829,059 , which was decreased by $11.32 \%$ compared to the year before implementation. The proportion of the outpatient volume of the Department of General Pediatrics to the total outpatient volume at 1 year after the implementation of the comprehensive registration

Table 3 Comparison of the proportion of patients who believed that waiting time needed improvement before and after the implementation of the comprehensive reservation service for non-emergency registration

\begin{tabular}{|c|c|c|c|c|c|}
\hline Time & Before implementation(\%) & Time & After implementation(\%) & $\begin{array}{l}\text { Difference between the latter } \\
\text { and the former (\%) }\end{array}$ & $P$ \\
\hline First quarter of 2015 & 59.76 & First quarter of 2016 & 48.58 & $\downarrow 11.18$ & 0.000 \\
\hline Second quarter of 2015 & 67.33 & Second quarter of 2016 & 49.80 & $\downarrow 17.53$ & 0.000 \\
\hline Third quarter of 2015 & 54.59 & Third quarter of 2016 & 45.42 & $\downarrow 9.17$ & 0.000 \\
\hline Fourth quarter of 2014 & 62.16 & Fourth quarter of 2015 & 48.81 & $\downarrow 13.35$ & 0.000 \\
\hline
\end{tabular}

$P<0.05$ : statistically significant 
Table 4 Comparison of outpatient satisfaction before and after the implementation of the comprehensive reservation service for non-emergency registration

\begin{tabular}{lllll}
\hline Time & $\begin{array}{l}\text { Before } \\
\text { implementation } \\
\text { (points: mean } \pm \text { SD) }\end{array}$ & $\begin{array}{l}\text { After implementation } \\
\text { (points: mean } \pm \text { SD) }\end{array}$ & & P \\
\hline First quarter & $80.32 \pm 13.30$ & $87.11 \pm 13.28$ & 16.529 & 0.000 \\
$\begin{array}{l}\text { Second } \\
\text { quarter }\end{array}$ & $82.18 \pm 13.36$ & $86.47 \pm 13.47$ & 10.348 & 0.000 \\
Third quarter & $80.51 \pm 13.59$ & $87.86 \pm 14.32$ & 17.053 & 0.000 \\
$\begin{array}{l}\text { Fourth quarter } \\
81.68 \pm 13.60\end{array}$ & $86.64 \pm 14.48$ & 11.439 & 0.000 \\
$\begin{array}{l}\text { Overall mean } \\
\text { value }\end{array}$ & $81.17 \pm 13.90$ & $87.02 \pm 13.62$ & 13.749 & 0.000 \\
\hline$P<0.05$ statistically significant & & & & \\
\hline
\end{tabular}

service was $21.83 \%$, which was decreased compared to 1 year before the implementation of the comprehensive registration service (23.01\%).

\section{Discussion}

Our study showed that the patient waiting time was significantly decreased after implementing the comprehensive reservation service for non-emergency registration. The proportion of patients who believed that waiting time needed improvement was decreased, and outpatient satisfaction was improved significantly. The total outpatient volume was lower than that before the implementation of the comprehensive reservation service, indicating that the outpatient volume was effectively controlled. After the implementation of the comprehensive reservation service for non-emergency registration, the medical service process was simplified and optimized by mobile registration and payment. Our hospital shared our experience of implementing a comprehensive reservation service for non-emergency registration with colleagues in other hospitals throughout the country. On January 3, 2018, our hospital was awarded the "2015-2017 National Quality Service Demonstration Hospital" award.

The significant increase in the appointment registration rate was evaluated. China's medical system is obviously defined based on Chinese characteristics. In European and North American countries [11-13], most clinicians require patients to make appointments in advance for medical consultations. If a patient has a disease but no emergent condition, the primary care provider directly contacts a specialist in a hospital and makes arrangements for further diagnosis and treatment of the patient.
The average waiting time of patients was decreased after the implementation of the comprehensive reservation service for non-emergency registration.Our experience showed that improvements in service optimization processes also reduced the difficulty in seeing a doctor, consistent with the opinions of many researchers in China and abroad $[14,15]$. The registration service could facilitate improved follow-up of patients. Moreover, it is the basis of continuous service, and the need for registration service is also the consensus of medical service researchers [16]. Singapore has established percentile targets for appointment lead-times for patients because appointment postponements are regarded as unacceptable for health care services [17]. Recent studies have shown that the accessibility for patients can be significantly improved by applying simple methods and performing barrier analyses [18].

This study was different from those in other countries, which might be because of the following reasons. The development of a variety of patient-friendly appointment registration methods was necessary to successfully implement the comprehensive reservation service for nonemergency registration. A previous survey study showed that the dimensional score of "promoting appointment services and effectively diverting patients" was decreased [19]. The study found that whether the appointment registration rate could be improved or not depended on the convenience of the appointment registration method. The previous study agreed with our results. Mobile applications collect data from patients regarding their eating habits, body weight and overall health status through weekly surveys [20]. As our hospital is the largest women and children's hospital in South China, patients come to our hospital from all over the country. Some of the patients come from large cities, while some of the patients come from rural areas. Moreover, the education levels of patients are different; there are young patients as well as some elderly patients with children. Considering these factors, our hospital offered a several methods for registration as previously mentioned; patients chose their method of registration according to their preference.

Because of the mobile payment systems for online registration, there was no need to obtain a paper registration certificate at the hospital, which shortened the waiting time. A long waiting time for a medical consultation has become an important factor affecting outpatient satisfaction $[21,22]$. It was necessary to conduct

Table 5 Comparison of the annual monthly outpatient volume before and after the implementation of the comprehensive reservation service for non-emergency registration

\begin{tabular}{|c|c|c|c|c|}
\hline Year & Monthly outpatient volume & Difference & $\mathrm{t}$ & $P$ \\
\hline One year before implementation & $338,552 \pm 43,654$ & - & - & - \\
\hline One year after implementation & $316,520 \pm 32,876$ & $22,032 \pm 24,153$ & 3.160 & 0.009 \\
\hline
\end{tabular}




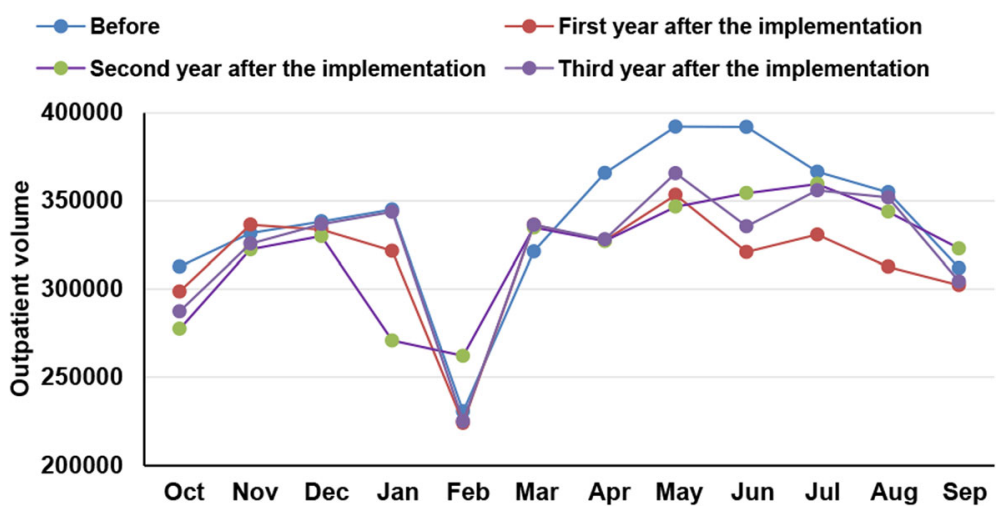

Fig. 2 Monthly outpatient volume one year before and three years after the implementation of the comprehensive reservation service for non-emergency registration

more research on medical health applications in children's health care centers to ensure the quality and reliability of mobile health applications [23].

Activities to strengthen publicity should be conducted through media campaigns. Pidgen TE [24] noted that parents had limited information regarding appointment setting. Therefore, we solicited the opinions and suggestions of patients and their family members as well as clinical departments to develop the "Explanation of 17 common problems of patients and their family members" and "Implementation details of the comprehensive reservation service for non-emergency registration" guidance documents. To ensure understanding, these documents contain plain language and cartoons and other pictures. In addition, our hospital has carried out many promotional campaigns employing various media platforms such as television, websites, the WeChat public platform, newspapers, display screens, leaflets and so on.

This study showed that the total outpatient volume of our hospital was decreased and effectively controlled after the implementation of the comprehensive reservation service for non-emergency registration, further assisting in grading diagnosis and treatment, consistent with the results of Wang who noted that the outpatient volume in a department was decreased after health care reform in Beijing [25]. Before the implementation of the comprehensive reservation service for non-emergency registration, the hospital admitted all patients who visited the hospital. After the implementation of the comprehensive reservation service, medical resources were allocated in an organized way. For example, when the appointment of the Department of General Pediatrics was full, patients with some common complaints such as cold and fever could visit the nearest district-level hospital, and those who needed actual specialist treatment could be seen at our hospital. This, in turn, decreased the outpatient volume of the Department of General Pediatrics and decreased the total outpatient volume. The role of tertiary hospitals was thus played, and the grading diagnosis and treatment were also observed. Referral service is an important part of medical reform in China [26]. Continuous attention should be paid to the reservation and referral tracking [27].

\section{Limitations}

The results of this study are based on the research data of one hospital, the Guangzhou Women and Children's Medical Center. Additionally, the data collection time was limited.

\section{Conclusion}

In this study, the changes after the implementation of the comprehensive reservation service for non-emergency registration in a Chinese hospital were summarized. To optimize medical service processes and meet the needs of patients, hospitals need to improve processes and information distribution. The implementation of the comprehensive reservation service for non-emergency registration decreased the patient waiting time and improved patient satisfaction, indicating that this program achieved the intended results in a Grade 3A Hospital in China.

\section{Supplementary information}

Supplementary information accompanies this paper at https://doi.org/10. 1186/s12913-019-4652-6.

Additional files 1. Attachment1-Satisfaction Questionnaire.

\section{Acknowledgments \\ We thank the Guangdong Situation Research Center for their help in collecting the data. We also thank Doctor Chen for the statistical analysis contribution.}

\section{Authors' contributions}

WHX designed and carried out the study, collected data, and drafted the manuscript. XFY and XJC participated in the analysis design, collected data and the creation of new software used in the work. PYL participated in the design, acquisition of data and draft the manuscript. All authors contributed to manuscript preparation and approved the final manuscript. 


\section{Funding}

WHX received funding from the Guangzhou Science and Technology Project (NO: 201806020047), Guangzhou Institute of Pediatrics/Guangzhou Women and Children's Medical Center (IP-2016-010). The funders had no role in study design, data collection and analysis, decision to publish, or preparation of the manuscript.

\section{Availability of data and materials}

The datasets used and/or analyzed in the current study are available from the corresponding author upon reasonable request.

\section{Ethics approval and consent to participate}

The study received approval from the Ethics Committee of Guangzhou Women and Children's Medical Center (SFE-KL-23701), and patients or patient guardians signed an informed consent form before participation.

\section{Consent for publication}

Not applicable.

\section{Competing interests}

The authors declare that they have no competing interest.

\section{Author details}

'Department of outpatient, Guangzhou Women and Children's Medical Center, Guangzhou Medical University, Guangzhou, China. ${ }^{2}$ Department of Science, Education and data Management, Guangzhou Women and Children's Medical Center, Guangzhou Medical University, Guangzhou, China. ${ }^{3}$ Department of pediatrics, Guangzhou Women and Children's Medical Center, Guangzhou Medical University, Guangzhou, China.

Received: 16 April 2019 Accepted: 17 October 2019

Published online: 01 November 2019

\section{References}

1. Godley M, Jenkins JB. Decreasing wait times and increasing patient satisfaction: a lean six sigma approach. J Nurs Care Qual. 2019;34(1):61-5.

2. Cabello JJ, Garcia D, Sagastume A, Priego R, Hens L, Vandecasteele C. An approach to sustainable development: the case of Cuba. Environ Develop Sustain. 2012;14(4):573-91.

3. Jarvis S, Livingston J, Childs AM, Fraser L. Outpatient appointment nonattendance and unplanned health care for children and young people with neurological conditions: a retrospective cohort study. Dev Med Child Neurol. 2019;61 (7):840-6.

4. Herd TJ, Nopper AJ, Horii KA. Effect of a referral-only policy on wait time for outpatient pediatric dermatology appointments. Pediatr Dermatol. 2017; 34(3):369-70.

5. Shan J, Bamgbade B, Barner JC, Klein-Bradham K, Janiga X, Brown B. Impact of telephone and mail intervention on appointment adherence and clinical outcomes among patients with diabetes. J Pharm Health Serv Res. 2014; 5(1):3-9.

6. Huang YL, Marcak J. Grid patient appointment template design to improve scheduling effectiveness. J Healthc Eng. 2015;6(2):239-58.

7. Ortiz Barrios MA, Felizzola JH. Use of six sigma methodology to reduce appointment Lead-time in obstetrics outpatient department. J Med Syst. 2016;40(10):220.

8. China SHaFPCotpsRo. Circular on Issuing the Action Plan for Futher Improving Medical Care Services. Chinese Medical Practitioners 2015;No. 2[EB/OL].

9. Randolph LA, Walker CK, Nguyen AT, Zachariah SR. Impact of pharmacist interventions on cost avoidance in an ambulatory cancer center. J Oncol Pharm Pract. 2018;24(1):3-8.

10. Keshvani N, Hon M, Gupta A, Brown TJ, Roy L, Marley E, et al. Reducing Hospitalizations: Institution of Outpatient Infusional EPOCH-Based Chemotherapy at a Safety Net Hospital. J Oncol Pract. 2019:Jop1800738.

11. Hsiang WR, Lukasiewicz A, Gentry M, Kim CY, Leslie MP, Pelker R, et al. Medicaid patients have greater difficulty scheduling health care appointments compared with private insurance patients: a meta-analysis. Inquiry. 2019:56:46958019838118.

12. Goldstein IH, Hribar MR, Read-Brown S, Chiang MF. Association of the presence of trainees with outpatient appointment times in an ophthalmology clinic. JAMA Ophthalmol. 2018;136(1):20-6.
13. Seghieri C, Calovi M, Ferre F. Proximity and waiting times in choice models for outpatient cardiological visits in Italy. PLoS One. 2018;13(8):e0203018.

14. Salman OH, Rasid MF, Saripan MI, Subramaniam SK. Multi-sources data fusion framework for remote triage prioritization in telehealth. J Med Syst. 2014;38(9):103.

15. Hang SC, Hassmiller Lich K, Kelly K, Howell DM, Steiner MJ. Patient- and visit-level variables associated with late arrival to pediatric clinic appointments. Clin Pediatr (Phila). 2017;56(7):634-9.

16. Tatham A, Murdoch I. The effect of appointment rescheduling on monitoring interval and patient attendance in the glaucoma outpatient clinic. Eye (Lond). 2012;26(5):729-33.

17. Nguyen TB, Sivakumar Al, Graves SC. A network flow approach for tactical resource planning in outpatient clinics. Health Care Manag Sci. 2015; 18(2):124-36.

18. Johannessen KA, Alexandersen N. Improving accessibility for outpatients in specialist clinics: reducing long waiting times and waiting lists with a simple analytic approach. BMC Health Serv Res. 2018;18(1):827.

19. Liu XN, Luo L, Bai G. Ea. evaluation of the implementation of healthcare improvement initiative at China's tertiary hospitals. Chin J Hosp Admin. 2016;32(6):415-8.

20. de Bruin JS, Schuh C, Seeling W, Luger E, Gall M, Hutterer E, et al. Assessing the feasibility of a mobile health-supported clinical decision support system for nutritional triage in oncology outpatients using Arden syntax. Artif Intell Med. 2018;92:34-42.

21. Kalb LG, Freedman B, Foster C, Menon D, Landa R, Kishfy L, et al. Determinants of appointment absenteeism at an outpatient pediatric autism clinic. J Dev Behav Pediatr. 2012;33(9):685-97.

22. Prentice JC, Davies ML, Pizer SD. Which outpatient wait-time measures are related to patient satisfaction? Am J Med Qual. 2014;29(3):227-35.

23. Morse SS, Murugiah MK, Soh YC, Wong TW, Ming LC. Mobile health applications for pediatric care: review and comparison. Ther Innov Regul Sci. 2018;52(3):383-91.

24. Pidgeon TE, Blore CD, Webb Y, Horton J, Evans M. A patient information leaflet reduces parental anxiety before their Child's first craniofacial multidisciplinary outpatient appointment. J Craniofac Surg. 2017;28(7):1772-6.

25. Wang ZQ, Li YZ. Study on health care reform and its influence on changes of outpatient quantity and countermeasures. Hosp Manag Forum. 2017; 34(12):8-10

26. Zhang $X$, Wang $T$, Yu Y, Zhao $S$. Key nodes affecting patient satisfaction in a cross-regional referral service process: an empirical analysis study in Sichuan. BMC Health Serv Res. 2018;18(1):840.

27. Ray KN, Drnach M, Mehrotra A, Suresh S, Docimo SG. Impact of implementation of electronically transmitted referrals on pediatric subspecialty visit attendance. Acad Pediatr. 2018;18(4):409-17.

\section{Publisher's Note}

Springer Nature remains neutral with regard to jurisdictional claims in published maps and institutional affiliations.

\section{Ready to submit your research? Choose BMC and benefit from:}

- fast, convenient online submission

- thorough peer review by experienced researchers in your field

- rapid publication on acceptance

- support for research data, including large and complex data types

- gold Open Access which fosters wider collaboration and increased citations

- maximum visibility for your research: over $100 \mathrm{M}$ website views per year

At $\mathrm{BMC}$, research is always in progress.

Learn more biomedcentral.com/submissions 